DOI: http://doi.org/10.52716/jprs.v11i3.536

\title{
الاحكام القانونية لشركة توزيع المنتجات النفطية
}

\section{Legal provisions of the Oil Products Distribution Company}

\author{
محمل جاسم تحمث
}

Oil products Distribution Company

Author Email; muhammadjassem80@ gmail.com

Received 18/1/2021, Accepted 9/6/2021, Published 19/9/2021

ان شركات النفط العالمية تعيش مرحلة ايجابية من تزايد ربحيتها كأثر ناتج عن التغير الايجابي الذي طر أ على التى التي

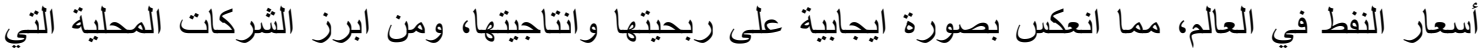

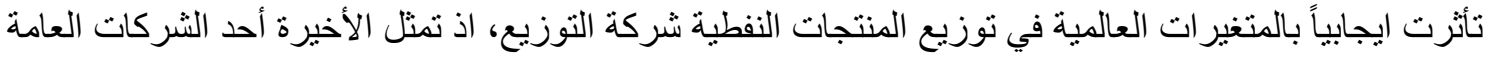

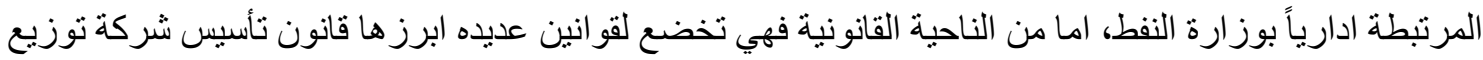

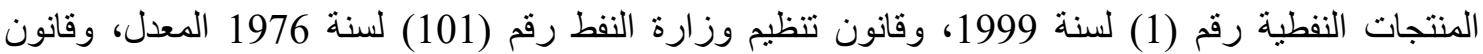

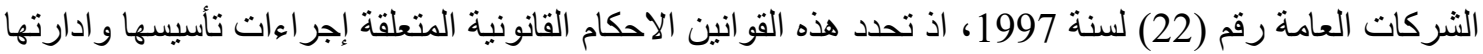

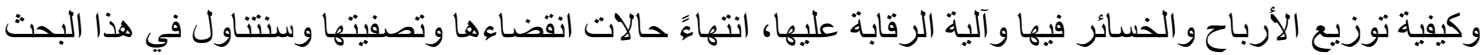
اهم الاحكام القانونية المتعلقة بشركة التوزيع.

\section{$\underline{\text { Abstract }}$}

The international oil companies have a good budget of increasing profitability as a result of the positive change in the world oil prices, which has reflected positively on the profitability and productivity of international oil companies, and the most prominent domestic companies that were positively affected by global variables is the oil products distribution company products as a one of the public companies that are administratively associated with the Ministry of Oil. In legal terms, however, it is subject to several laws, most notably the Law for the Establishment of Oil Products Distribution Company No. (1) of 1999, the Law of Organization of the Ministry of Oil No. 101 of 1976, Public companies No. (22) for the year 1997 can be determined these laws and legal provisions concerning the establishment, management and how the distribution of profits and losses in which the mechanism of oversight procedures, the 


\section{Journal of Petroleum Research and Studies}

Open Access

No. 31, June 2021, pp.20-38

end of the cases it expires, filtered, and we will discuss in this paper the most important legal provisions relating to the distribution of petroleum products company.

فكرة البحث:

تز ايدت أهمية النفط في الآونة الأخيرة، حيث أصبحت له أهية كبرى للصناعة العالمية، لذا أظهرت تللك الأهمية ضرورة ملحة للصناعة الهامة التي لا يمكن الاستغناء عنها في العالم، فالولايات المتحدة الأمريكية تقوم وحدها باستهلاك ربع الاستهلاك العالمي، وهو ما يقرب من ثمانين مليون برميل يو مياً، وبذللك تصبح أكبر مستهلك للنفط في العالم، كما ظهرت العديد من المنظمات النفطية من أجل السيطرة على أسواق النفط مثل منظمة "الدول المصدرة للبترول" والتي تضم في عضويتها اثتنا عشر دولة تعتمد في اقتصادها على النفط اعتماداً كبير اً، أما على منى التى مستوى الدول العربية فقد ظهرت منظمة "الأوابك" التي تهتم بشؤون النفط بين الدول الأعضاء ومن بينها نوزيع النفط، اذ نوجد ست شركات نفطية كبرى تهنم بالنفط ومشتقاته، والتي ظهرت في نهاية التسعينيات بسبب كساد تجارة النفط، إذ اندمجت تلك الثركات النفطية من اجل محاولة تحسين أوضاعها المالية والاقتصادية وزيادة الاستثمار ات النفطية المشتركة بينهم في مجال النفط، بالإضافة إلى الرغبة في اتخاذ إجراءات احترازية ضد تقلبات أسعار المنتجات النفطية.

تجدر الإشارة الى انه يوجد حوالي ست شركات نفطية عالمية كبرى متخصصة في مجال النفط ولكنها شركات خاصة أي لا تخضع للحكومات وغير مملوكة للدولة، وهذه الثركات هي: إكسون موبيل وشل وبي بي وشيفرون وكونوكو فيلبس ونونال، وقد دمج شركتي بي بي وأموكو، سنة 1998 وتلتها شركة أكسون وموبيل في عام 1999م، كما اندمجت موبيل مع شركة بتروفينا البلجيكية عام 1999م، ثم بعد ذلك مع شركة ألف في عام 2000م، واندمجت شركة شيفرون النفطية مع تكساكو، وشركة كونوكو مع شركة فيليس بتروليوم، حيث تمت تلك الاندماجات في حوالي 10 سنوات من عام 1998م وحتى عام 2002م، وقد تم تتظيم اندماج هذه الثركات بموجب الاحكام القانونية المنصوص عليها في قوانين الدول التابعة لها. اما في العراق، فقد نأثر توزيع المنتجات بمر احل زمنية أدت الى تطور نشاطه رافق ذلك ظهور مجموعة من القوانين التي تتظم الجوانب القانونية له، ففي البداية نشاط شركة التوزيع يدار قبل عام 1952 من قبل شركة الر افدين.

تجدر الإشارة الى أن إدارة نشاط التوزيع تحول في عام 1952 الى شركة نفط خانقين المحدودة، وتأسست أول مؤسسة حكو مية تمارس نشاط التوزيع وتحمل اسم (مصلحة توزيع المنتجات النفطية)، وبعد خطوة أخرى بالغة الأهمية تم انشاء المؤسسة العر اقية لتعبئة الطائر ات بالوقود و الزيوت 1967، كثركة مساهمة بين العراق وشركة 


\section{Journal of Petroleum Research and Studies}

Open Access

No. 31, June 2021, pp.20-38

JpRe

P- ISSN: 2220-5381

E- ISSN: 2710-1096

تونال الفرنسية، ثم تم الحاق هذه المؤسسة بمصلحة توزيع المنتجات النفطية 1972، وتم تسميتها (مديرية تعبئة الطائر ات بالوقود).

وقد طر أ تغير مهم على نشاط المنتجات النفطية في عام 1986، إذ نم الغاء المؤسسة العامة، وتقرر توزيع نشاطها على اربعة منشآت جغر افية في المناطق، هي المنطقة الثمالية والمنطقة الوسطى، ومنطقة الفرات الأوسط و المنطقة الجنوبية، وألحق بها كل من منشأه خطوط الانابيب وشركة النقل.

كما حدث تغيير مهم عام 1988 اذ تم الغاء كافة المنشآت واستحداث (شركة توزيع المنتجات النفطية)، وفي 1988/8/28، وفي 1991/1/2 ادمجت شركة النقل والمنشاة العامة لخطوط الانابيب مع شركة التوزيع لتصبح مسؤولة عن نشاط التوزيع في العراق، ثم نم اعادة تنظيم هيكلية نشاط التوزيع في 1993/9/25 ونم استحداث ثلاثة منشآت هي: (المنشأة العامة لتوزيع المنتجات النفطية) و(المنشاة العامة لتعبئة الغاز) و(المنشاة العامة لخطوط الانابيب)، ووفق الهيكلية اعلاه اصبحت المنشأة العامة لتوزيع المنتجات النفطية مسؤولة عن نشاط الثركات الثلاثة أعلاه، وقد رافق التطور التاريخي تطور قانوني، اذ خضعت في نشاطها الى قانون تنظيم وزارة النفط رقم (101) لسنة 1976، ثم صدر بعد ذللك قانون تأسيس شركة توزيع المنتجات النفطية رقم (1) لسنة 1999 المعدل، مع الإشارة الى ان هذه الثركة تخضع فيما لم يرد له نص في القانونين المذكورين الى الاحكام العامة في قانون الثركات العامة رقم (22) لسنة 1997 باعتباره الثريعة العامة للأحكام القانونية للثركات.

\section{أهمية البحث:}

يعد موضوع الاحكام القانونية من اهم الموضوعات الجديرة بالدراسة، إذ ترجع أهميته الى اهمية شركة التوزيع، اذ نعد الأخيرة حلقة استر اتيجية في سلسلة عمليات الصناعة النفطية، فتنصب أهمية نشاطها في حقيقة كونه مرتبطاً بحياة المواطنين سواء المستهلكين بصورة مباشرة أو مستهلكي هذه المنتوجات للأغراض الصناعية و التجارية.

وتتولى الشركة تأمين المنتجات للمو اطنين وتزويد المولدات الاهلية و الحكومية في عموم البلاد بوقود زيت الغاز وتصريف انتاج المصافي من الغاز السائل و البنزين ووقود الطائرات والديزل وزيت الغاز من خلال ادارة وتشغيل منافذ البيع المتمنلة بمحطات التعبئة وساحات الغاز و النفط وتترف على نشاط التوزيع في (1352) محطة تعبئة وقود و (2070) ساحة غاز ونفط موزعة في المحافظات العر اقية اضافة الى امتلاكها لأسطول نقل (1287) سيارة عاملة لنقل المنتجات، ولدى الثركة ورش ومعامل كبيرة تضم العديد من الاقسام الفنية المنتوعة اهمها معملي الدورة والمدائن لصيانة الثاحنات مع فرق متخصصة للفحص الهندسي والسيطرة النوعية ومختبرات فحص المنتوج قبل تسويقه، فكل هذه الأسباب وغيرها أدت الى تنامي الأهمية القانونية لار اسة هذا الموضوع وتسلبط الضوء على الجو انب القانونية له المتعلقة به. 


\section{Journal of Petroleum Research and Studies}

Open Access

No. 31, June 2021, pp.20-38

إشكالية البحث:

تتركز إنكالية البحث في إثارتها للعديد من الأسئلة التي تسلط الضوء على الاحكام الأساسية لثركة التوزيع و آلية تنظيمها قانوناً، وأهمها ما المقصود بشركة توزيع المنتجات النفطية؟ اذ ان القانون لم ينولى تعريفها في قانون تأسيسها ولم يحدد عناصر ها الرئيسية وهذا نقص تشريعي ينبغي تلافيه. ومن أبرز الأسئلة المثارة في هذا البحث، يتمثل في خصوصية نشاط الشركة؟ وما الذي يميزها عن بقية

$$
\text { الشركات العامة. }
$$

كما يثار تساؤل ايضاً حول عضوية هذه الثركة وكيفية ادارتها؟ وكيفية توزيع أرباحها وخسائر ها؟.

$$
\text { منهج البحث: }
$$

سنعتمد في دراسة هذا الموضوع على المنهج الوصفي التحليلي مستعرضاً النصوص القانونية التي عالجت الاحكام القانونية للشركة، ومن أبرز ها قانون تأسيس الثركة رقم (1) لسنة 1999، وقانون تنظيم وزارة النفط رقم (101) لسنة 1976 المعدل، وقانون الشركات العامة رقم (22) لسنة 1997 وسنحاول مناقتتها وتحليلها بهدف الخروج بنتائج ونوصيات.

\section{خطة البحث:}

تقتضي در اسة موضوع الاحكام القانونية أن نقسم هذا البحث إلى مبحثين ، سنخصص المبحث الأول ماهية شركة توزيع المنتجات النفطية، وسنقسمه الى ثلاثة مطالب نتناول في المطلب الأول التعريف بشركة التوزيع، وسنبين في المطلب الثاني سمات شركة التوزيع، وسنوضح في المطلب الثالث نشاط الثركة، اما المبحث الثاني جاء بعنوان ادارة وتوزيع أرباح الثركة، وسنقسمه الى مطلبين، نبين في المطلب الأول كيفية إدارة شركة التوزيع ونوضح في الثاني توزيع الأرباح، ثم ننهي البحث بخاتمة توضح جو هر ما توصل اليه الباحث من نتائج وتوصيات. 


\section{Journal of Petroleum Research and Studies}

Open Access

No. 31, June 2021, pp.20-38

jeps

P- ISSN: 2220-5381

E- ISSN: 2710-1096

\section{المبحث الأول}

\section{ماهية شركة التوزيع}

شها القطاع النفطي العيد من التطورات منذ عام 2003 كان لبعضها اثار ايجابية وللأخرى اثار سليبة؛ ونتيجة لللك حقق القطاع بعض النجاحات وعانى في نفس الوقت من اخفاقات عليدة ومؤثرة ساهمت بمجملها في اولا خلق حالة من التطور غير المنوازن في القطاع ذاته وثانيا في ادامة وترسيخ الخلل الهيكلي للاقتصاد العراقي والمتمثل بتعميق

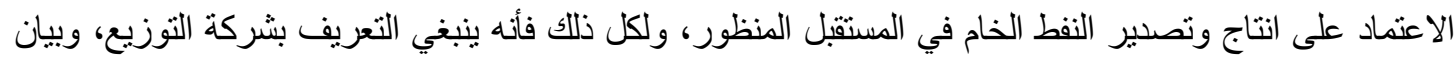
خصائصها وطييعة النشاط الذي تزاوله هذه الثركة وكيفية تحقيقها لهذا النشاطو هذا ما سنتخاوله في مطالب ثلاثثة.

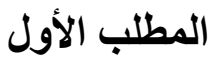

\section{التعريف بشركة التوزيع}

لتعريف الثركة أعلاه بقتضي الرجوع الى النصوص القانونية الواردة في قانون الثركة ذاتها باعتباره

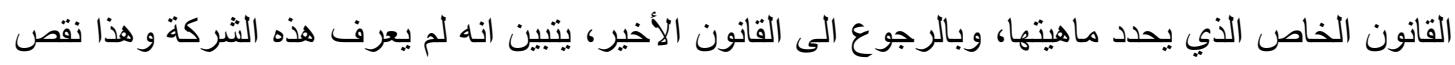

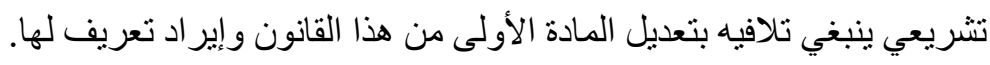

ان خلو القانون أعلاه من إيراد تعريف خاص بشركة التوزيع يحيلنا الى قانون الثركات العامة رقم (22)

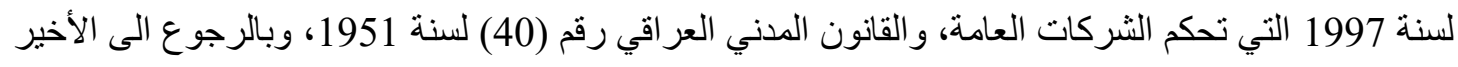

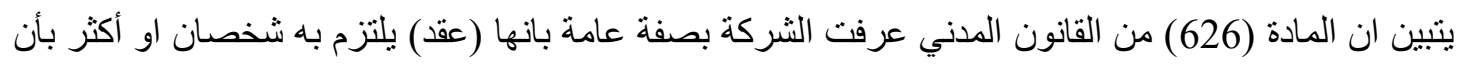

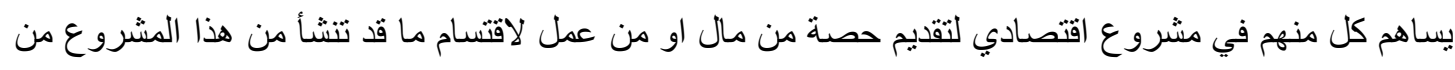
ربح او خسارة [1]

هذا كقاعدة عامة تخص الثركات التجارية التي تخضع لإحكام القانون رقم (21) لسنة 1997 اما فيما

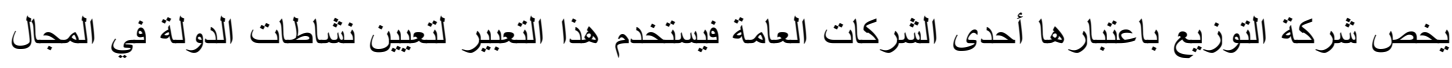

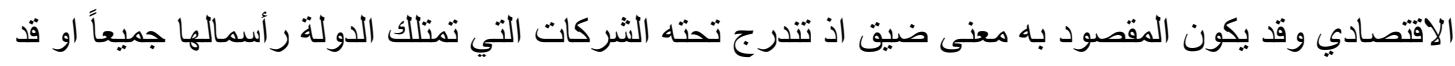

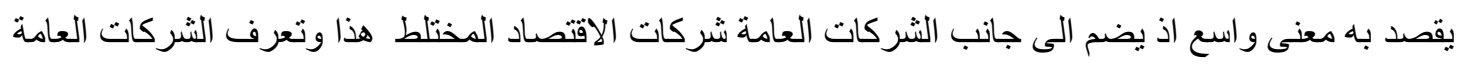

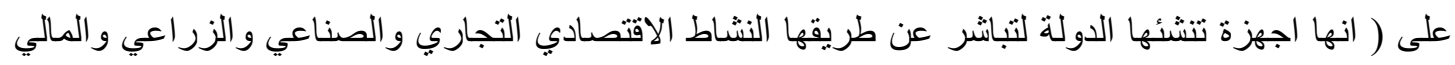
الذي اصبح من صميم اختصاصها في ظل النظام الاشتر اكي).

ومما يلاحظ على هذا التعريف انه اعتبر الثركات العامة اجزةة حكومية وتخضع للقانون الذي يحكم هذه

$$
\text { الاجهزة الا وهو القانون الاداري. }
$$




\section{Journal of Petroleum Research and Studies}

Open Access

No. 31, June 2021, pp.20-38

وذهب رأي آخر من الفقه الى تعريف الثركة العامة بانها (تللك التي اسستها الحكومة او احدى المؤسسات العامة بمفردها واصبحت هي المالك الوحيد لها وكذلك الثركات التي اممتها الحكومة وابقت لها شكلها القانوني كثركة)).

اما في مصر فنجد المشرع المصري قد عرف شركات القطاع العام بموجب القانون رقم (60) لسنة 1971 بانها ((وحدة اقتصادية تقوم على تنفيذ مشروع اقتصادي وفقا لخطة التنمية)) [2].

كما تعرف شركات القطاع العام بانها (وحدة اقتصادية يمنحها القانون الثخصية المعنوية وتقوم على تنفيذ مشروع اقتصادي سواء أكان صناعيا ام زر اعيا او تجاريا او ماليا لتحقيق اهداف التنمية الاقتصادية التي تضع الدولة خطتها)) [3].

ومما يلاحظ على هذه التعاريف انها لم تبرز اهم عناصر الثركة العامة الا وهو ملكية الدولة للثركة، او طبيعة الذمة المالية وكونها ملكية عامة. وذهب رأي آخر من الققه الى تعريف الثركة العامة بانها (مشروع عام يقوم بنشاط ذو صفة انتاجية او استهلاكية يهدف الى تحقيق هدف من اهداف الخطة ويخضع لنظام قانوني خاص).

ان الثركة العامة تتدرج ضمن مفهوم المشروع العام الذي كثير اً ما يتخذ شكل (شركة عامة او مؤسسة عامة او منشاة عامة). ويعرفها المشرع العام على ((انه ذمة مالية مستقلة تنشئها الدولة وتضفي عليها الثخصية المعنوية لتأكيد

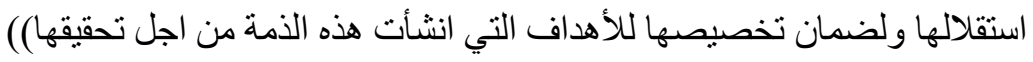

وان هذا التعريف لم يبرز بصورة واضحة اهم عناصر المشروع العام وهو ملكية الدولة للذمة المالية وطبيعة هذه الملكية كونها ملكية عامة، وفي فرنسا يعرفه المستشار (ديلون) بانه (ذمة مالية عامة مشخصة مخصصة لمهمة (قتصادية). وان هذا التعريف يشير الى ان فكرة المشروع العام يقوم على اساس الملكية العامة وعنصر وظيفي هو التخصص للنشاط الاقتصادي مما يؤدي الى تحديد مهمة او وظيفة المشرو عات العامة.

وذهب رأي من الفقه الى تعريف المشروع العام بانه (منظمة تتمتع بالثخصية المعنوية زودتها الدولة براس المال بقصد تنفيذ نشاط اقتصادي او تجاري وفقاً لخطة التنمية التي تضعها الدولة، وتتبع بصفة اساسية وسائل القانون الخاص). 


\section{Journal of Petroleum Research and Studies}

Open Access

No. 31, June 2021, pp.20-38

كنلك يعرف المشروع العام بأنه (اجتماع عنصري الامو ال العامة والاعمال المخصصة لإتمام الخطة في شخص قانوني يخضع لنظام قانوني مزدوج) [4]. وبالنظر إلى التعريف أعلاه فإنه يتضمن عناصر المشروع العام وهي الاموال العامة والعمل لإتمام الخطة وكنلك الخضوع لنظام قانوني مزدوج [5]. تجدر الإشارة الى ان بعض الفقه قد أنكر على المشروع العام صفة الثركة اذ ان المشروع العام ليس شركة والقول بغير ذلك يمكن ان يعد مجرد افتراض وذيوع التنسية لا يمكن ان يغير حقيقة المسمى مع انتشار تعبير الثركة العامة. ونعتقل ان هذا التعبير أصبح خاليا في اذهان الناس من معنى التعدد الذي هو جوهر فكرة الثركة وان المشروع العام ليس شركة لأنه ليس فيه من عناصر الثركة شيء فهو لا يستتد الى عقد ولا يتضمن تعددا وليس

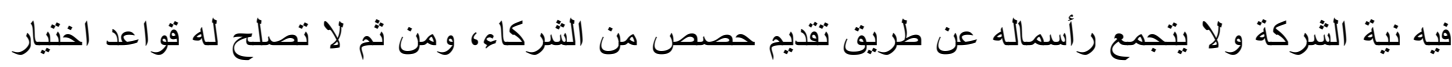
اعضاء مجلس الادارة و لا التز اماتهم مثل تقديم أسهم الضمان.

اما بالنسبة للمشرع العراقي فقد عرف الثركة العامة بموجب المادة الاولى من قانون الثركات العامة

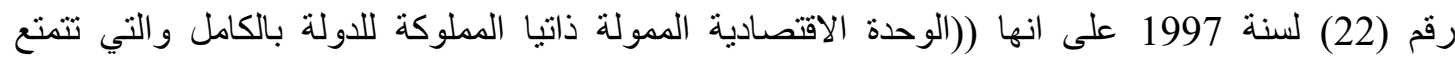

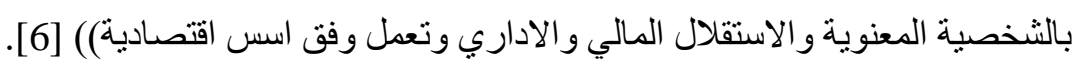

وييدو ان المشرع قد اخذ بالمغنى الضيق للثركات العامة أي انه قصر تعريف الثركات العامة على الثى

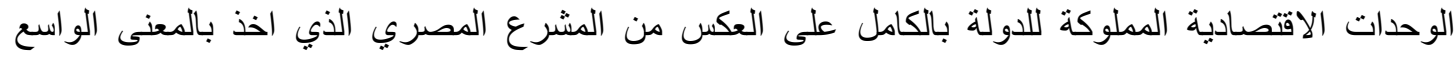

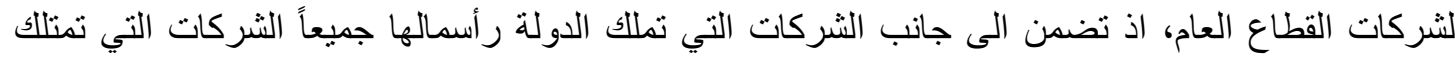
الدولة فيها ما يزيد على 51\% من امو الها وذلك بموجب المادة (18) من قانون هيأت القطاع العام وشركاته رقم

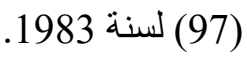

يظهر من التعريفات المتقدمة ان شركة التوزيع تعد وحدة اقتصادية مستقلة مالياً و ادارياً وممولة ذاتياً من وزارة النفط، لذا من الممكن ان نعرفها بأنها شركة عامة مملوكة بالكامل للاولة، ادار اتها لامركزية وتتمتع بالثخصية المعنوية وتمارس نشاطاً اقتصادياً وتخضع لمزيج من قو اعد القانون العام والخاص معا. 


\section{Journal of Petroleum Research and Studies}

Open Access

No. 31, June 2021, pp.20-38

jeRs

P- ISSN: 2220-5381

E- ISSN: 2710-1096

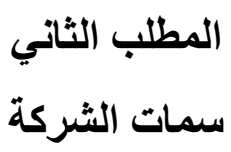

تتسم شركة التوزيع بمجموعة من السمات تميزها عن غيرها من الثركات العامة في العراق، ان هذه السمات ابرزت خصوصيتها و اكسبتها طابعاً مميز اً، وسنتناول در استها فيما يأتي:

اولاً: وحدة اقتصادية لتوزيع النفط: فلكل مشروع وفي اي نظام قانوني غرضا وهو النشاط الاساسي الدائم الذي تقوم على اساسه الصفة الاقتصادية للمشروع، فتمارس الثركة نشاطا اقتصاديا سو اءً أكان زر اعيا ام صناعيا ام تجاريا ام ماليا وليس لها ان تتجاوز حدود الغرض الذي انثأت لتحقيقه.

ثانياً: ممولة ذاتياً: على الرغم من اعتماد مثل هذه الثركات على التمويل المركزي ولا سيما في بداية انشائها بالنسبة للمنشآت الحديثة فأنها ملزمة بأن تسير في نشاطها بما يحقق لها ارباحا تواجه بها التزاماتها وتوسعاتها فيجب ان تدار بصورة تحقق لها الكفاية والفاعلية، وان الاخذ بهذه السياسة هو من ظو اهر الانفراد المالي للشركة بمعنى اعتمادها على مو اردها الخاصة من رأسمالها ونسبة من فائض الأرباح، وقد حددت هذه السمة بوضوح في قانون تأسبس الثركة.

ثالثا: ملكية رأس مال الثركة للاولة: بمعنى انه لا يوجد حملة للأسهم و السندات وان الدولة هي المالكة الوحيدة للشركة وتعد هذه الاموال امو الا عامة تتمتع بالحماية المقررة قانونا لهذا النوع من الاموال بما لا يجوز حجزها و التصرف بها وتملكها بالتقادم على أساس عائديتها للدولة [7].

رابعاً: تمتع الثركة بشخصية معنوية قائمة: ان تأسيس الثركة يعني ظهور كائن قانوني له استقلاله المالي و الإداري، وعليه ان مصطلح الثركة ينصرف فضلا عن العقد، الى كيان اقتصادي ظهر بإجر اءات نطلبها القوانين، يتمتع بشخصية تصورية تتمتع بالحقوق وتفرض عليها واجبات بما بشبه الى حد كبير الأشخاص الطبيعية، ويؤدي هذا التصور الى استقلال الثخص المعنوي، بحيث تصبح العقود والأموال بمجرد تأسيس الشركة عائدة لها وليس للأشخاص الموقعين على عقد تأسيسها، ويستمر الثخص في العمل حتى ان خروج الشركاء من الثركة او موت أعضاء مجلس الإدارة فيها فلا يؤدي ذلك الى انتهاء الثركة تلقائياً [8].

وجدير بالذكر ان الثخصية المعنوية العنصر الاساسي لشركة التوزيع في مختلف التنظيمات القانونية و لأنواع الثركات النفطية كافة في مختلف الدول أياً كان النظام السائد فيها سواءً أكان في الدول التي تؤمن بالنظام الرأسمالي ام الاشتراكي وتعد الثخصية المعنوية السمة التي يتميز بها تدخل الدولة في النشاط الاقتصادي، ويترتب على منح الشخصية المعنوية النتائج الاتية: 


\section{Journal of Petroleum Research and Studies}

Open Access

No. 31, June 2021, pp.20-38

أـ الانفراد المالي: ان الانفر اد المالي للشركة العامة معناه انها تتمكن من تكوين مواردها المالية ومن ثم اختيار الاسلوب الذي يلائم انفر ادها وممارستها لنشاطها [9].

واول مظاهر الانفر اد لثركة التوزيع هو ان تكون لها حسابات خاصة بها منميزة من حسابات الدولة او الوزارة المرتبطة بها وكذللك ميزانية منفصلة عن الميز انية العامة استثناء من مبدا وحدة الميز انية، وهذا من شأنه ان يوفر لها استقلالاً مالياً. بـ الاستقلال الاداري: أبي استقلال الثركة بإدارة شؤونها بنفسها فملس ادارة الثركة ومدير ها العام هما الهيأتان المختصنان بالنظر في كل شؤون الشركة وقرارات مجلس الادارة نافذة من تلقاء نفسها فيما عدا الحالات

$$
\text { التي ينص قانون الثركات فيها على وجوب التصديق على هذه القرار ات [10]. }
$$

خامساً: تعمل وفق اسس اقتصادية: ان الثركة العامة هي وحدة اقتصادية تختص بنوع من النشاط الاقتصادي سو آء كان صناعيا ام زراعيا او تجاريا او ماليا، وانها تتبع قواعد الادارة الاقتصادية لأنها تتحمل المسؤولية الرئيسة في خطة التنمية القومية لان راس المال الخاص لا يمكن ان يتولى بنفسه خطة التنمية لعدم قدرته على توفير الموارد اللازمة لعملية التنمية كما ان راس المال الخاص لا يدخل الميادين الجديدة للاستثمار التي تنطوي على قدر كبير من المخاطرة، وان هذه القو اعد في القطاع الخاص وحدها قواعد تطبيقية قد اصبحت قو اعد شبه قانونية يلتزم بها المشروع العام وان منها فضلاً عن التخصص الاقتصادي، التوازن المالي، وتحقيق الربح وتركز

$$
\text { المشرو عات [11]. }
$$

هذه هي اهم الصفات الواجب تو افرها في المشروع العام لكي يتخذ شكل الشركة العامة و لا سيما في العر اق هذا فضلاً عن خضوع هذه الشركات لنظام رقابة منميز من الحكومة، على ان هناللك من يرى بان للمشروع العام عناصر اساسية في مختلف التشريعات و الانظمة القانونية المتباينة ومهما اتخذت الاشكال القانونية للمشروعات العامة أي سواء اتخذت شكل (الثركة العامة او المؤسسة العامة او المنشاة العامة) و هذه العناصر هي:

(1) تخصيص المشروع العام للنشاط الاقتصادي لضمان تحقيق اهداف الخطة. (2) تملك الدولة لر أس مال المشروع العام.

يكتسب المشروع العام شخصية معنوية مستقلة عن شخصية الدولة. (4) (4) التسجيل في السجل التجاري. بعد ان بينا التعريف بالثركة وحددنا خصائصها و عناصر ها بقي لنا لاستكمال البحث في ماهية هذه الثركة تحديد نشاط الثركة الذي يميزها عن بقية الثركات العامة في العراق وسنتناول تحديده بالتفصيل في المطلب 


\section{Journal of Petroleum Research and Studies}

Open Access

No. 31, June 2021, pp.20-38

Jpers

P- ISSN: 2220-5381

E- ISSN: 2710-1096

\section{المطلب الثالث

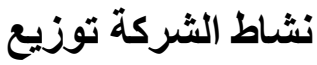

اما بالنسبة لنثاط شركة التوزيع، فيعد الأخير من المستلزمات الأساسية للثركات عموماً ولثركة التوزيع خصوصاً، وقد حددت المادة (3) من قانون تأسيس شركة توزيع المنتجات النفطية رقم (1) لسنة 1999 أوجه النثاط الذي تزاوله هذه الثركة واشارت الى ان الثركة تمارس بغية تحقبق اهدافها الانشطة التالية وفق أحكام قانون تنظيم

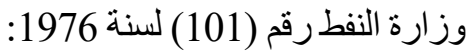

$$
\begin{aligned}
& 1 \text { - استلام وخزن المنتجات النفطية في مستودعاتها. } \\
& 2 \text { - نقل المنتجات النفطية من المستودعات و المعامل الى منافذ البيع التي تدار من قبل الثركة. } \\
& 3 \text { - ادارة وتثغيل منافذ بيع المنتجات النفطية التابعة للثركة في عموم العراق. } \\
& 4 \text { - الاشر اف على منافذ بيع المنتجات النفطية التي تدار من قبل القطاع الخاص. } \\
& 5 \text { - بيع المنتجات النفطية الى المو اطنين و المؤسسات القطاعية. } \\
& 6 \text { - المشاركة في تنفيذ عقود تصدير المنتجات النفطية. } \\
& 7 \text { - تنفيذ عقود نقل المنتجات النفطية بالسيار ات داخل العراق وخارجه. } \\
& 8 \text { - ادارة وتتفيذ جميع الاعمال الفنية و الخدمية بما يدعم أنتطنها. }
\end{aligned}
$$

من الجدير بالذكر ان المادة سابقة قد اشارت ايضاً الى الوسائل التي تكفل لثركة التوزيع تحقيق نشاطها

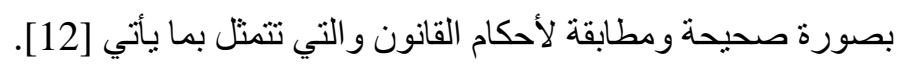

حيث أجاز المشرع استير اد وشراء وبيع وايجار واستئجار وسائط النقل والاجهزة والمعدات والآلات و الادوات الاحتياطية وغير ها من المواد والمستلزمات الاخرى، كما سمح المشرع العراقي بممارسة الاعمال

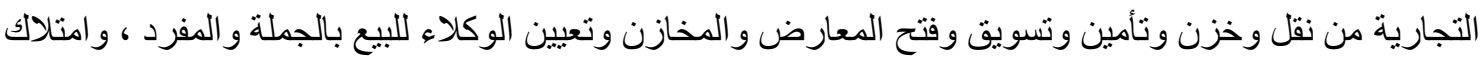

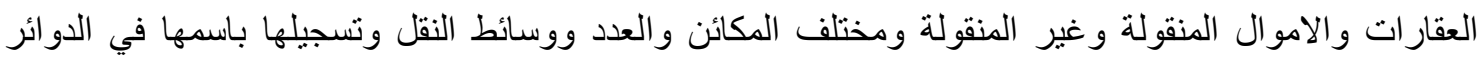

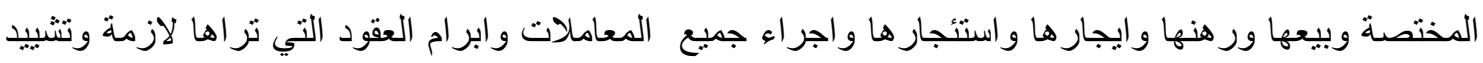

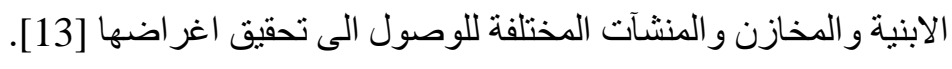




\section{Journal of Petroleum Research and Studies}

Open Access

No. 31, June 2021, pp.20-38

jeps

P- ISSN: 2220-5381

E- ISSN: 2710-1096

فضلاً عن ذلك فقد سمح بأجر اء المناقصات و المز ايدات و الدخول في مختلف التعهدات مع سائر القطاعات

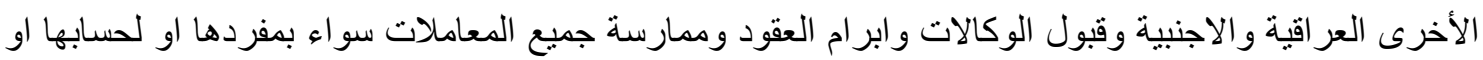

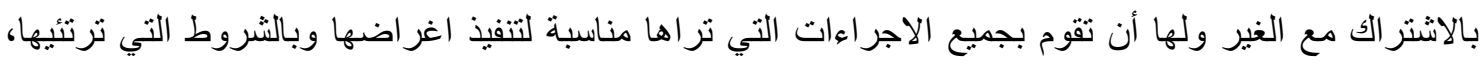

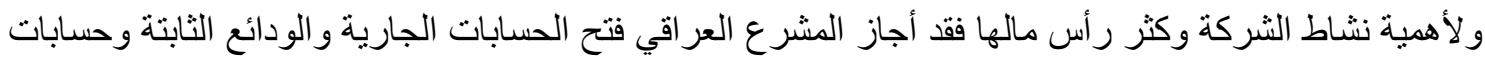

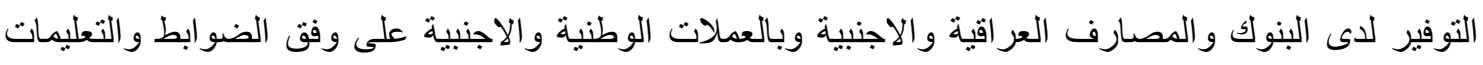

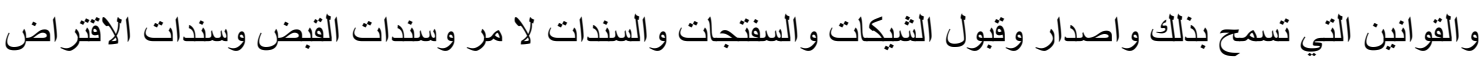

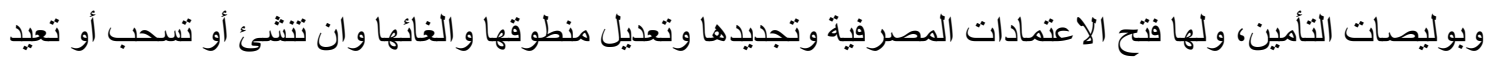

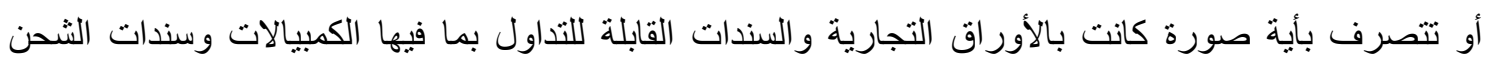

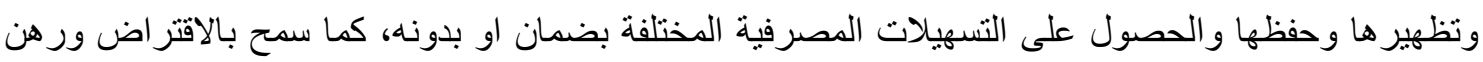

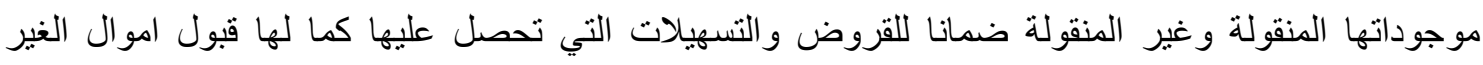
المنقولة وغير المنقولة وارتهانها ضمانا لديون الثركة وحقوقها تجاه الغير من الدينين او المنعاملين معها.

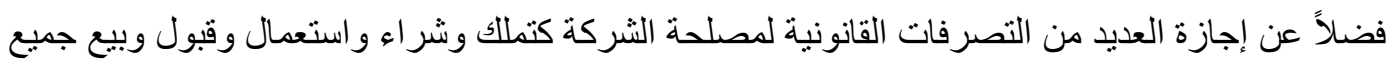

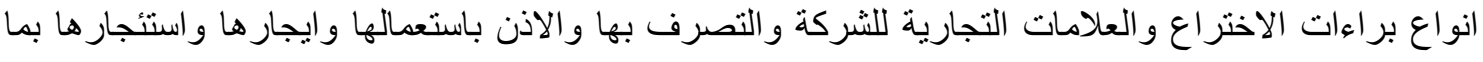

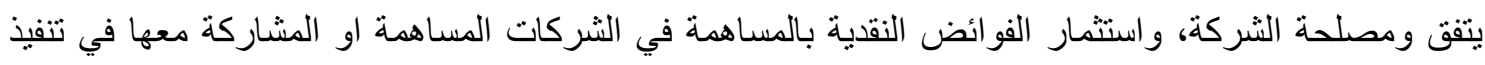

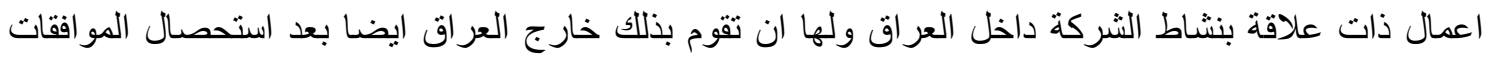
اللازمة [14] واستثمار الفوائ النقدية في الثركات والمؤسسات العربية والاجنبية او المشاركة معها في تنفيذ

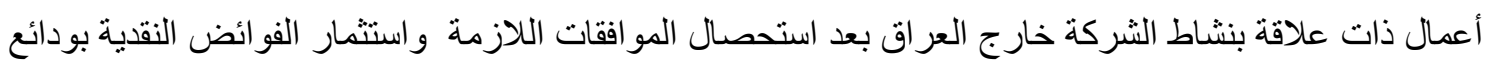

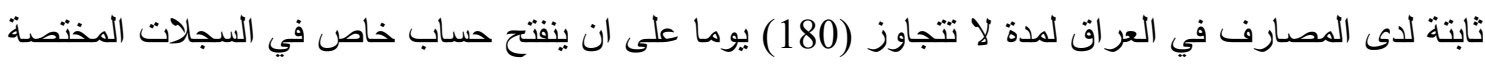
لغرض تثبيت الفو ائد المستحقة عن تلك الودائع لإظهار ها في الحسابات الختامية بما يضمن كفاءة الاداء في نشاطها و الاقر اض والاقتراض او الحصول على الاموال لتمويل نشاطها ومشاريعها من المؤسسات المالية و الثركات

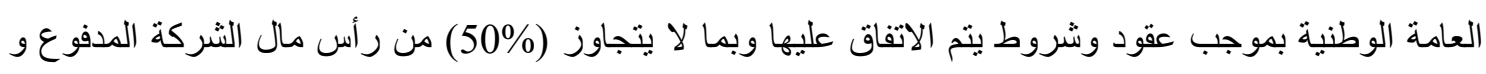
الاقتر اض من خارج العراق لتمويل نشاط الثركة الاستثاري و الجاري بعد استحصال المو افقات اللازمة.

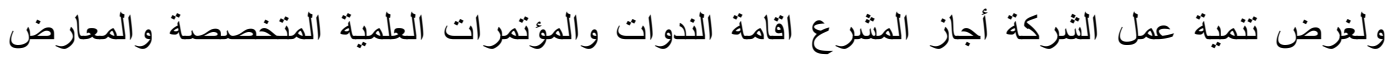

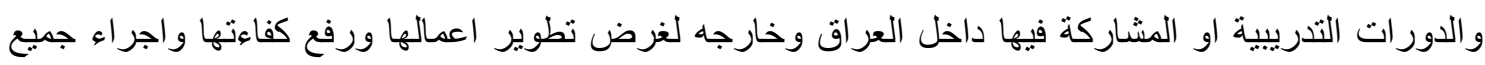

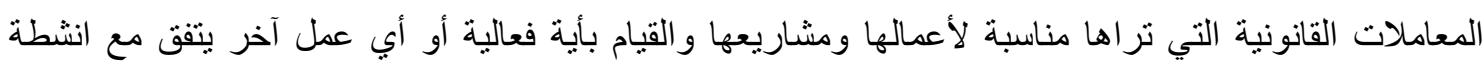

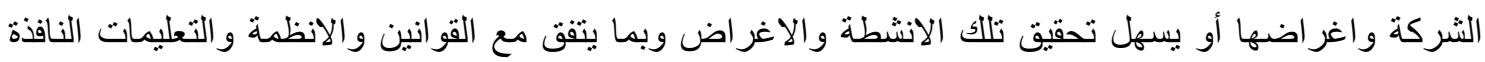




\section{Journal of Petroleum Research and Studies}

Open Access

No. 31, June 2021, pp.20-38

خلاصة ما تقام أن قانون التأسيس لم يعرف الثركة الا ان هذا الامر لا يعيب هذا القانون لأن ادراج التعريفات القانونية هو من اختصاص الفقه وليس التشريع، فالأخير يختص بتقرير الاحكام القانونية ويترك للفقه مهمة اير اد التعريفات القانونية كل حسب الاتجاه الذي ينظر له لهذا الموضوع، وبينا ان شركة توزيع المنتجات النفطية هي شركة عامة ومن ثم فأن تحديد مفهومها يخضع من حيث الأصل الى القواعد القانونية التي تحكم الثركات العامة المنصوص عليها في قانون الثركات العامة رقم (22) لسنة 1997، باستثناء الاحكام الخاصة التي

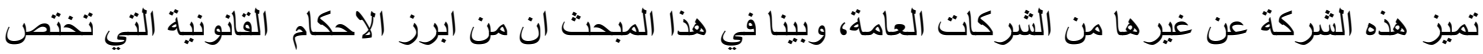

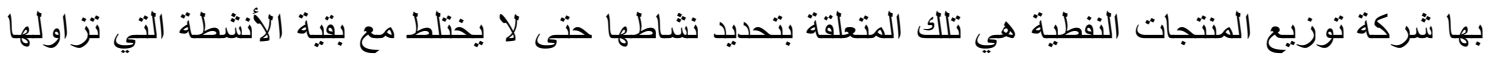

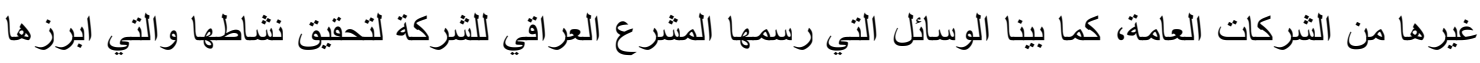

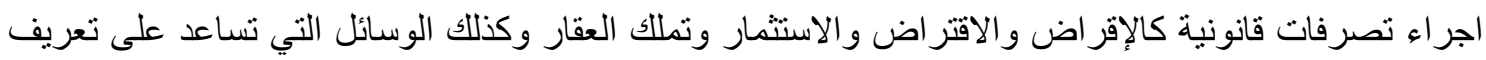
بقية الثركات بهذه الثركة منها عقد مؤتمر ات وندوات لتسليط الضوء على نثاطعها.

\section{المبحث الثاني \\ إدارة وتوزيع ارباح الشركة}

تتصف شركة التوزيع بالتتظيم، لذلك فأنه يعهد بأدارة الثركة الى الدير العام وتسعى الثركة بصفة عامة لتحقيق الربح وقد يؤول مسعاها الى الخسارة ولكل ذلك فسنتناول در اسة إدارة الثركة وتوزيع أرباحها في المطليين الآتيين.

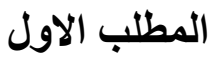

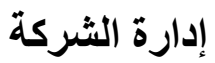

لاثشك في أهية الإدارة في تطور الثركة او اخفاقها بوصفها شركة عامة فأن ادارتها تناط بمجلس

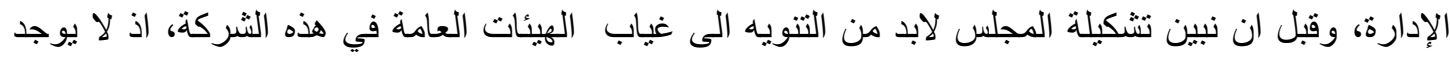

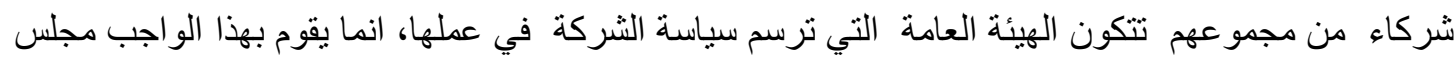
الإدارة، ولذلك فهو الذي يضع الخطط للثركة وهو الذي ينفذها، وعليه فأن مجلس الإدارة يضع السياسات والخطط الإدارية والفنية والمالية اللازمة لتحقيق اهداف الثركة، كما يقوم بالأشراف ومتابعة تنفيذ هذه الخطط،

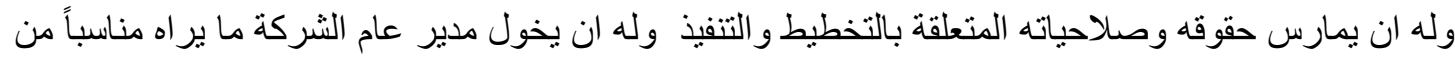
الصلاحيات التي يرى من الضروري منحها للمدير يقوم بها نيابة عن المجلس الذي لا يمكن ان يكون في حالة انعقاد مستمرة لمتابعة تتفيذ الخطط التي وضعها. 


\section{Journal of Petroleum Research and Studies}

Open Access

No. 31, June 2021, pp.20-38

jeps

P- ISSN: 2220-5381

E- ISSN: 2710-1096

اما بخصوص عضوية المجلس فينكون مجلس الادارة من تسع أعضاء اصليين هم المدير العام للثركة رئيساً الذي يعين بقرار من مجلس الوزراء من ذوي الاختصاص وان يحمل الثهاد الجامعية الأولية في الأقل، وثمانية

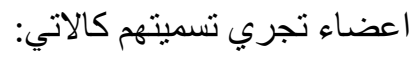

اولاً ــ أربعة اعضاء يختار هم الوزير من بين رؤساء النتكيلات في الثركة من ذوي الخبرة والاختصاص في الامور المتعلقة بنشاطها [16]. ثنانياً - عضو ان ينتخبان من منتسبي الثركة.

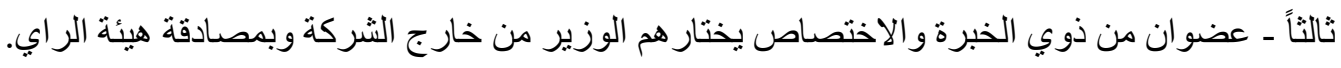
رابعاً ـ يكون لمجلس الادارة ثلاثة اعضاء احتياط ينتخب المنتسبون أحدهم ويعين الوزير العضوين الاخرين. خامساً - ينتخب المجلس في اول اجتماع له نائبا للرئيس من بين اعضائه ويحل محل الرئيس في حالة غيابه.

ومن المعلوم بأنه لا يوجد تلازم بين ملكية رأس المال و العضوية في مجلس الادارة، وقد لاحظنا ان الأعضاء الثمانية ومثلهم الاحتياط يصنفون الى ثلاث جهات الأولى تثمل رؤساء التثكيلات في الثركة يختار

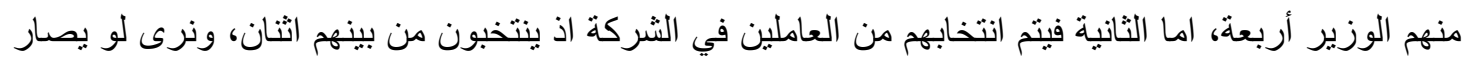
انتخاب الأربعة و الاثثين، ليكون المنتخب (6) من العاملين في الثركة ولا بأس ان يحدد (4) منهم من قبل رؤس التساء

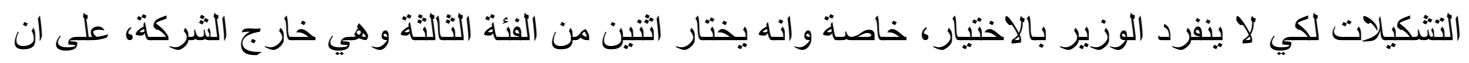

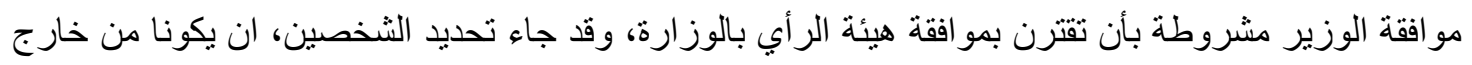

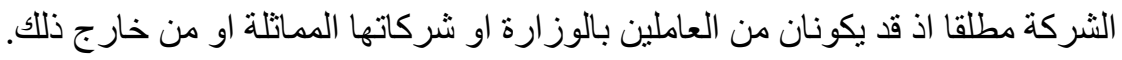

اما بقية الاحكام المتعلقة بإدارة الثركة، فأن مدة دورة المجلس (3) سنوات قابلة للتجديد تبدأ من تاريخ اول

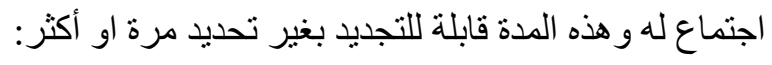
اولاً - يجتمع المجلس مرة واحدة في الشهر بدعوة من رئيسه.

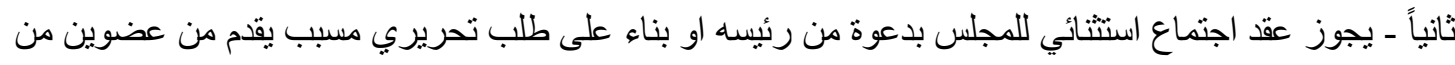
اعضائه [17].

ثالثاً ـ يحصل النصاب في اجتماعات المجلس بحضور اغلبية اعضائه بضمنهم رئيس المجلس او نائبه وتتخذ

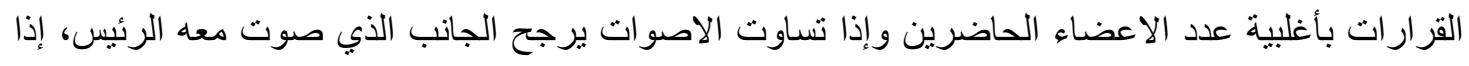
شغرت عضوية في مجلس الادارة، يدعو رئيس المجلس العضو الاحتياط من الصنف الذي حصل الثناغر فيه لإكمال المدة المتبقية من دورة المجلس تنفذ قرار ات المجلس عند صدور ها، عدا ما يتعلق منها بالأمور الاتية فتتفذ التهن

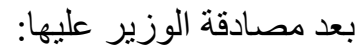




\section{Journal of Petroleum Research and Studies}

Open Access

No. 31, June 2021, pp.20-38

$$
\begin{aligned}
& \text { اولاً ــ الخططو الموازنات السنوية. } \\
& \text { ثانياً ـ الحسابات الختامية و التقرير السنوي للشركة. }
\end{aligned}
$$

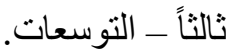

$$
\begin{aligned}
& \text { رابعاً ـ نظم حو افز الانتاج وتعتبر من ضمن كلفة الانتاج [18]. }
\end{aligned}
$$

و هذه الاعمال تكون عادة من اختصاص الهيئات العامة في الثركات الخاصة و المختلطة ومادام لا يوجد في هذه الشركات هيئات عامة، فيحل الوزير الذي تتبع الشركة وزارته، هذه الحالات الأربعة مما لا يجوز إضافة حالات

$$
\text { أخرى لها، لأنها وردت حصراً. }
$$

تعتبر قرار ات المجلس في المادة (15) من هذا القانون مصادقاً عليها إذا لم يعترض عليها الوزير خلال مدة 25 خمسة و عشرون يوما من تاريخ تسجيلها في مكتبه، فاذا اعترض عليها، يعاد عرضها على المجلس في اول اجتماع يعقده، فاذا أصر على رايه، تعقد جلسة برئاسة الوزير للنظر في الموضوع ويكون القرار الصادر بأغلبية عدد الاعضاء الحاضرين نهائيا، يدير الثركة مدير عام من ذوي الخبرة والاختصاص ممن يحمل شهادة جامعية اولية في الاقل، يعين بقرار من مجلس الوزراء وهو الرئيس الاعلى للشركة ويقوم بجميع الاعمال اللازمة لإدارتها وتسيير نشاطها وفق الصلاحيات الممنوحة له من مجلس الادارة [19].

\section{المطلب الثاني \\ توزيع ارباح الشركة}

بسعى الثركاء للحصول على الربح، ولكن قد يؤول مسعاهم الى الخسـارة، فيقتـي ان ينقاسم الثركاء الربح و الخسارة، و هو ما يعبر عنه بنيـة المشـاركة ، و المقصود بـالربح الزيادة الإيجابية في الذمهة المالية، او هي زيـادة في الأصول على الخصوم بموجب جرد سنوي واعداد ميز انية، كما هو معروف في الفكر المحاسبي، فلا بـ من الاشـارة بهذا الخصوص في البداية الى ان الهذف الاساسي من انشاء هذه الثركات العامة وشركة توزيع المنتجات النفطية هو تحقيق النفع العام ومن ثم فهي لا تقصد تحقيق الربح وان الربح الذي تحققه هذه الثـركات هو اثر من الاثار المترتبـة على طبيعتها فطالما انها تقوم بنشاطات اقتصادية تثبه الاعمال التي تقوم بها المشرو عات الخاصة ومن ثم يكون عليها اتباع الاساليب المشابهة للأسـاليب التي تتبع في ادارة المشروعات الخاصـة ومنها مر اعاة تحقيق الاربـاح، وبموجب قانون الثركات العامة رقم (22) لسنة 1997 الذي تسري احكامـه على الثـركات العامـة جميعها التي تزاول مختلف النشاطات الاقتصادية نصت المادة (11) منه على النسب التي ينم فيها توزيع الربح القابل للنوزيع وقد عرفت المـادة المذكورة الربح على انه زيادة الاير ادات على المصروفات الظاهرة في حساب الارباح و الخسائر للسنة المالية للنـركة المنظم على وفق التشـريعات النافذة و الانظمـة و الاعر اف المحاسبية المعتمدة و المدقق من فبل ديوان الرقابـة الماليـة 


\section{Journal of Petroleum Research and Studies}

Open Access

No. 31, June 2021, pp.20-38

JpRe

P- ISSN: 2220-5381

E- ISSN: 2710-1096

و الدصادقة عليه من الجهة الدخولة قانونـا. على انه وبموجب هذا القانون تستبعد الارباح و الخسائر الرأسمالية واية

ارباح او خسائر ناتجة عن النشاط غير الاعتيادي للثركة من الربح الصافي لأغراض توزيع حصة العاملين [20].

و لا يزيد الربح القابل للتوزيع على ما مقداره 30\% من كلفة النشاط الجاري ويوزع التنبقي على الثكل الاتي:[21]

(أ) نسبة 10\% من المبلغ الفائض عن الربح القابل للتوزيع و عده احتياطي راس مال تعويضا لفروقات الاندثار على التى

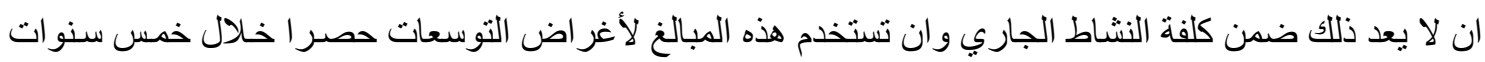
وبخلافه تحول المبالغ المذكورة الى وزارة المالية.

(ب) نسبة 40\% من الفائض عن الربح القابل للتوزيع في الثركات العامة و التابعة للقطاع الصناعي وتسجل في

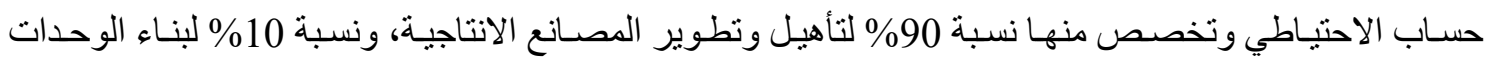
السكنية وتطوير خدمات السكن الحالي للمنتسبين و الملاحظ على هذه المادة انها قد اعتمدت كلفة النشاط الجاري

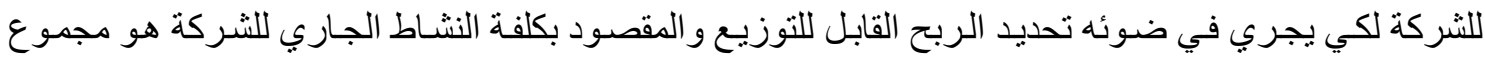
المصاريف التي انفتتها الثركة خلال السنة المالية وهذه المصاريف تكون (حساب 31 ولغاية حساب 37).

مما يدفع الثركات العامة الى رفع مصاريفها او نفقاتها الذي يؤدي الى زيادة الربح القابل للتوزيع ويجري توزيع نسبة 30\% من كلفة النشاط على وفق ما يأتي:

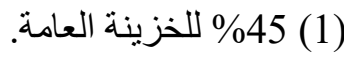

(2) 33 حو افز ربح لموظفي الثركة وللمتميزين منهم ولأعضاء مجلس الادارة وموظفي مركز الوزارة على الألى وفق نسب يضعها مجلس الادارة وبمصادقة الوزير.

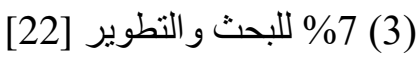
(5) 5 5 5 (3) للخدمات الاجتماعية للعاملين. (5) المتبقي لاحتياطي راس المال. وقد تولت مجالس الادارة في الثـركات العامـة وضع انظمـة النسب المذكورة في البنــ (2) اعلاه التي اقترنت بمصادقة الوزير.

ان نسبة المنتسبين المشار اليها بالقانون تتضمن فضلا عن النسبة المخصصة العاملين في الثركة العامـة نسبة مركز الوزارة و التي تصل في بعض الوزارات الى نسبة 8\% وهي نسبة كبيرة إذا مـا قورنت بعدد منتسبي

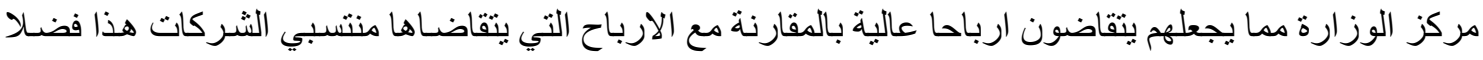




\section{Journal of Petroleum Research and Studies}

Open Access

No. 31, June 2021, pp.20-38

عن استقطاع نسبة 20\% من حو افز ربـح موظفي الثشركة العامـة وعده حو افز لمنتسبي الدفاع وقوى الامسن

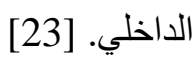

مما يجعل حو افز الربح التي يجري توزيعها على العاملين بالثركة لا يتجاوز 70\% من النسبة المذكورة في

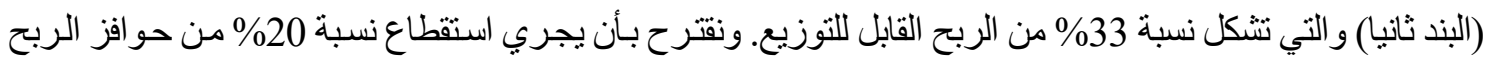

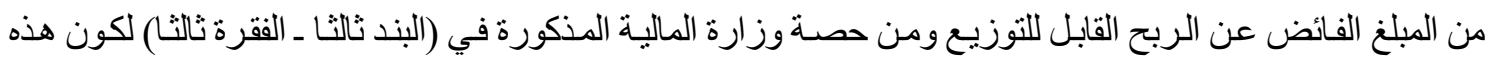
النسبة تنثل حو افز ربح لموظفي الثركة.

ويصنف المنتسبين لغرض منح حو افز الربح الى فئات لا تزيد عن ثماني حصص. وحسب هذه الفئات تتزراوح هذه الحصص من (3-8) على ان يؤخذ بالحسبان الامور الاتية عند تحديد الفئة [24]: أ) المستوى القيادي للمنتسب تخصص له 35 \% ب) دور المنتسب في الانتاج تخصص له 40\%.

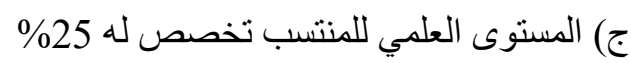
وتحدد حصة المنتسب من حافز الربح على الوجه الاتي:

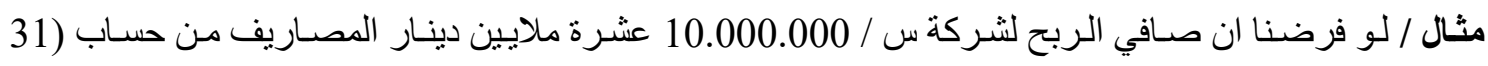
ولغاية 37) من النظام المحاسبي الموحد والتي تثتنمل على (الرواتب والاجور والمستلزمات السلعية، المستلزمات

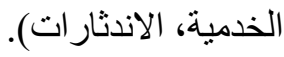

تمثل 9.000 .000 تسعة ملايين دينار وينزل منها التغيير في مخزن الانتاج التام / 640.000 دينار وينزل منها التغيير في مخزن الانتاج غير التنام / 340.000 دينار المتبقي للينا يمثل كلفة النشاط الجاري 8.000 .000 مليون دينار كلفة النشاط الجاري (8.000.000) × 30\% = 2.400 .000 يمثل الربح القابل للتوزيع. نستتج مما تقدم ان المشر ع العر اقي لم ينص في قانون تأسبس شركه توزيع الهنتجات النفطية على آلية معينة لتحديد كيفية

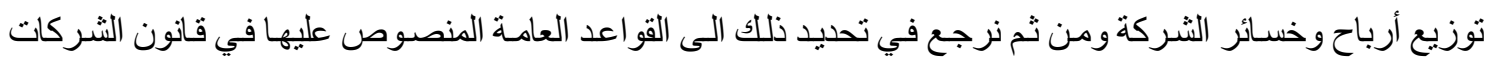

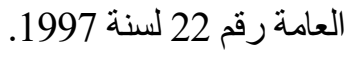




\section{Journal of Petroleum Research and Studies}

Open Access

No. 31, June 2021, pp.20-38

1. الشرع العر اقي لم يعرف شركة التوزيع و هذا نقص ينبغي تلافيه بإير اد تعريف لهذه الشركة يميزها عن بقية الشركات النفطية. 2. ان توزيع الأرباح والخسائر في شركة التوزيع يخضع للقو اعد العامة في قانون الثركات العامة رقم (22) لسنة

3. حدد المشرع العراقي نشاط شركة التوزيع المنتجات النفطية في قانون تأسيسها، وكان الاجدر بالمشرع ان يحددها على سبيل المثال ليفسح المجال امام الأنثطة التي تستجد في المستقبل. 4. ان ادارة شركة النوزيع بأسلوب اللاهركزية المرفقية.

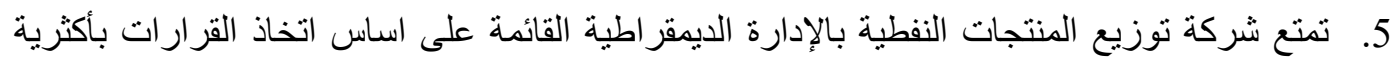
عدد الاعضاء الحاضرين ولكن هذه الديمقراطية قد تصادر فيما يخص الصلاحيات المعطاة لمجلس

$$
\text { الادارة بتحويل صلاحياته الى الدير العام. }
$$

6. ان نظام الادارة في شركة التوزيع يقوم على ازدواج دور المدير العام فهو من جانب الرئيس الاعلى العى لللشركة ومن جانب اخر رئيس مجلس ادارتها. 7. يتبين من الدراسة توافر العناصر الاساسية التي تقوم عليها فكرة المؤسسة العامة في شركة توزيع المنتجات النفطية وذلك من خلال الثخصية المعنوية والاستقلال المالي و الاداري الذي منحه القانون

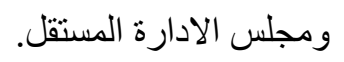
8. تعد شركة التوزيع من المر افق العامة الاقتصادية و التي تخضع للقو اعد العامة. 9. تعتبر شركة التوزيع شخصاً ممولة ذاتياً. 10. تتفق الانظمة الداخلية جميعها بالأحكام الواردة فيها وفي عدد المواد التي تتضمنها على الرغم من اختلاف الغرض الذي وجدت من اجله هذه الثركات.

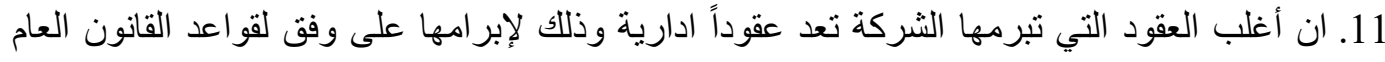
سواء ما يتعلق بطر ائق ابرام هذه العقود ام ما يتعلق بتضمين هذه العقود بعض امتيازات القانون العام. 


\section{Journal of Petroleum Research and Studies}

Open Access

No. 31, June 2021, pp.20-38

[1] د. لطيف جبر كوماني، الثركات التجارية (دراسة قانونية مقارنة)، ط1، مكتبة السنهوري،2،2015،

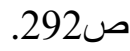

[2] د. احمد محرز، الوسيط في الثركات التجارية، ط2، منشأة المعارف، الاسكندرية، 2004، ص23. [3] سالم ريدعان، التخطيط الاشتراكي للتجارة الداخلية في العراق، رسالة ماجستير قدمت الى كلية القانون

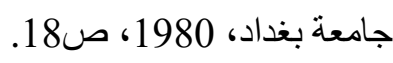
[4] باسم تحمد صالح، القانون التجاري، القسم الاول، مطبعة جامعة بغداد، العراق، 1987، ص239. [5] لطيف جبر كوماني، مصدر سابق، ص 294. [6] سالم ريدعان، مصدر سابق، ص20. [7] [حمد محرز، مصدر سابق، ص26.

[8] Gower ‘principles of modern company law ‘steven and son londom ‘1979 ‘p104.

[9] باسم تحمد صالح، مصدر سابق، ص240.

[10] عماد عبد الستار القصاب، مجالس ادارة الثركات العامة، بحث منشور في مجلة القانون المقارن، العدد31

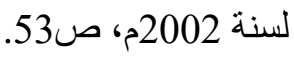

[11] لطيف جبر كوماني، مصدر سابق، ص 296.

[12] د. صفاء الحافظ، القطاع العام وافاق التطور الاشتر اكي في العراق دار الفارابي، بيروت، 1971م، 34. [13] د. فاروق جاسم، الموجز في الثركات التجارية، المكتبة القانونية، بغداد ، 2011، ص24. [14] د. باسم عحمد صالح، مصدر سابق، ص1313.

[15] حامد مصطفى، النظام القانوني للمؤسسات العامة والتاميم في القانون العر اقي، بغداد، 1965م، ص414. [16] عماد عبد الستار القصاب، مجالس ادارة الثركات العامة، بحث منشور في مجلة القانون المقارن، العدد 31 لسنة 2002م، ص28 (17) [17] د. غريب الجمال، الثركات المساهمة العامة، دار النهضة العربية، مصر، 1957م، ص43.

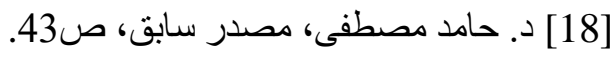

[19] د. ابراهيم عبد العزيز شيحا، مبادئ واحكام القانون الاداري اللبناني، دراسة مقارنة، الدار الجامعية

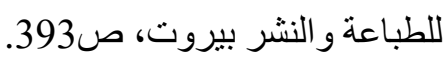
[20] قانون التعديل الثالث لقانون الثركات العامة بموجب القانون رقم 14 لسنة 2002 المنشور في جريدة الوقائع العر اقية العدد 3928 في 2002/4/28. [21] قانون التعديل الاول لقانون الثركات العامة / المصدر السابق. 


\section{Journal of Petroleum Research and Studies}

Open Access

No. 31, June 2021, pp.20-38

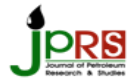

P- ISSN: 2220-5381

E- ISSN: 2710-1096

$$
\begin{aligned}
& \text { [22] تم تعديل هذه النسبة بموجب كتاب مجلس الوزر اء المرقم } 4634 \text { في 12/ايار } 2002 \\
& \text { [23] كتاب امانة مجلس الوزراء المرقم } 6300 \text { في 2000/8/28. } \\
& \text { [24] نظام وضو ابط توزيع الارباح للشركة العامة للتبوغ و السكاير. }
\end{aligned}
$$

